\title{
Bilateral Osteonecrosis of Femoral Head in Sickle Cell Disease: Salvage by Early Surgical Treatment in Single Sitting
}

\section{Sudhir Babhulkar* and Sushrut Babhulkar}

Department of Orthopaedic Surgery, Sushrut Hospital, Research Centre and Postgraduate Institute of Orthopaedics, Nagpur, India

*Corresponding Author: Sudhir Babhulkar, Department of Orthopaedic Surgery, Sushrut Hospital, Research Centre and Postgraduate Institute of Orthopaedics, Nagpur, India.

Received: August 29, 2019; Published: September 12, 2019

DOI: 10.31080/ASOR.2019.02.0101

\section{Abstract}

The aim of the study was to diagnose cases of osteonecrosis of femoral head in sickle cell disease commonly seen in Central India, and to perform the surgery of both hips in single sitting for early revascularization before the collapse in young patients. These patients in early stages causes minimal pain and discomfort, and are not diagnosed until deformity of femoral head has occurred. Despite a high incidence of bilaterality, only about $15 \%$ of patients reports with bilateral symptoms on initial presentation.

Total 44 patients with 88 femoral heads in stage II and III, were operated in single sitting. All hips with stage III were operated by core decompression and iliac crest-TFL muscle pedicle grafting by using part of iliac crest with Tensor Fascia lata (TFL) pedicle, whereas contralateral symptomatic/asymptomatic hips in stage II were operated by core decompression (Multiple drilling) only.

Results of the study showed good clinical improvement with relief of pain and improved range of movements in most of the patients. Majority of patients $70 \%$ of stage II and $30 \%$ of stage III had complete relief of pain and full functional recovery when operated in one sitting.

In conclusion Core decompression and TFL muscle pedicle bone grafting yields good to excellent results in early stages of II and III even if operated in single sitting. Ninety percent's patients in stage II and seventy two percent's in stage III had good results in osteonecrosis in Sickle cell disease patients.

Keywords: Osteonecrosis; Sickle Cell Disease; Femoral Head; Bilateral

\section{Introduction}

Sickle cell haemoglobinopathy is a genetic multisystem disease, which includes a group of disorders that differ in severity of signs and symptoms. The disease is commonly seen in specific community of scheduled caste and scheduled tribes in central India 1. It is now recognized that Sickle cell disease is a major musculo-skeletal problem mostly affecting the young people in their productive years of life [1-7]. Osteonecrosis of femoral head progresses despite treatment, resulting in to in severely disabling painful stiff hip because of sub-chondral fracture, collapse and painful arthritis [7].
Hence in this study the main aim was to diagnosis osteonecrosis of femoral head in patients with sickle cell disease early and salvaging both hips in a single setting surgery before collapse of femoral head. These patients were thoroughly investigated by Sickling and Solubility test and subsequently by Haemoglobin electrophoresis. Similarly in-patient of osteonecrosis of femoral head the opposite hip which was regarded as "high risk" patient and close watch was kept on such patient for at least two year.

It is crucial to diagnose the disease early, and the diagnosis begins with a complete physical examination, including questions 
about any other health conditions that may affect the bones and joints. Several imaging techniques are used to correctly diagnose osteonecrosis. Magnetic resonance imaging (MRI) is the most common technique for diagnosing Osteonecrosis in early stages.

The natural history of osteonecrosis of femoral head before the development of crescent sign or before the collapse of the femoral head has never been well understood. The possibility of progression to collapse is thought to increase after the development of crescent sign that can be seen on plain radiograph and such possibility may be highly variable and unknown. It is generally agreed that symptomatic, radiographically abnormal hip will progress to collapse of the femoral head when treated non-operatively [7-9].

\section{Material and Methods}

This article reports the prospective study of 79 patients of Sickle cell disease with osteonecrosis of femoral head, 44 patients with bilateral involvement 35 patients with unilateral involvement. Out of total 44 bilateral patients with 88 femoral heads in stage II and III, were operated in single stage in duration of 10 years from January 2008 to December 2017 and were followed with a mean of 7 years. All patients were young between 16-48 years of age with a mean age of 28 years. There were 26 males and 18 females in this study. All patients were screened and confirmed for Sickle cell disease. Amongst 44 patients 28 patients had homozygous involvement (SS pattern) and 16 patients had heterozygous (AS pattern).

All patients had positive axis deviation test, with loss of internal rotation of hips, which is highly suggestive of osteonecrosis of femoral head. All patients were investigated by X-rays, bone scan, MRI to ascertain the diagnosis and extent of involvement. All the patients were evaluated for Pain using VAS (Visual analogue scale) on the scale of 1 to 10 . The international classification system proposed by the Association Research Circulation Osseous (ARCO) has been used in this study (Table 1) [10]. Whenever bone scan was negative in such high-risk group of patients with strong clinical suspicion, the patients were subjected to sequential MRI.

The surgical management of Sickle cell disease demands medicinal treatment and a planned strategy for control of various factors, which can precipitate sickling or aggravate the already existing anaemic state. All these patients had medicinal treatment of Sickle cell disease including Soda bi carb, hydroxy urea, Zinc and folic acid.

The management aims at maintenance of a steady state of haemoglobin and avoidance of sickle cell crisis and factors that are known to precipitate sickling like hypoxia, acidosis, hypotension, peripheral circulatory stasis, hypothermia, dehydration, respiratory depression. Whenever possible, general anaesthesia was avoided and regional- spinal anaesthesia or epidural block was used. Measures to prevent hypothermia were taken which included prevention of excessive cooling of the operation theatre, which avoids vasoconstriction and peripheral stasis.

All hips with stage III were operated by core decompression and iliac crest-TFL muscle pedicle grafting by using part of iliac crest with Tensor Fascia lata (TFL) pedicle, whereas contralateral stage II asymptomatic hips were operated by core decompression (Multiple drilling) only [6]. In all these patients the changes were evident radio-logically before the collapse (II and III). There were 14 patients with bilateral stage III involving 28 hips and were operated by Core Decompression and TFL grafting. Whereas 30 patients had stage III involvement on one side, which were operated by core decompression and TFL grafting and stage II on contralateral side were treated by Core decompression only.

\section{Operative technique}

Patient after spinal anesthesia, were put in supine position with the sandbag underneath the gluteal region on the operative side. A straight incision is taken on lateral side of hip extending from

\begin{tabular}{|c|c|c|c|c|c|c|}
\hline Stage & $\mathbf{0}$ & 1 & \multicolumn{2}{|c|}{2} & 3 & 4 \\
\hline Findings & $\begin{array}{l}\text { All present tech- } \\
\text { niques normal or } \\
\text { non diagnostic }\end{array}$ & $\begin{array}{l}\text { X-ray and CT are } \\
\text { normal. At least } \\
\text { ONE of the below is } \\
\text { positive }\end{array}$ & \multicolumn{2}{|c|}{$\begin{array}{l}\text { No crescent sign: } \\
\text { X-RAY Abnormal: } \\
\text { Sclerosis, lysis, focal } \\
\text { porosis }\end{array}$} & $\begin{array}{l}\text { Crescent Sign on the } \\
\text { X-ray and/or flattening } \\
\text { of articular surface of } \\
\text { femoral head }\end{array}$ & $\begin{array}{l}\text { Osteoarthritis joint } \\
\text { space narrowing, } \\
\text { acetabular changes, } \\
\text { joint destruction }\end{array}$ \\
\hline Techniques & $\begin{array}{c}\text { X-ray } \\
\text { CT } \\
\text { Scintigraphy } \\
\text { MRI }\end{array}$ & $\begin{array}{c}\text { Scintigraph } \\
\text { MRI } \\
\text { *Quantitate on MRI }\end{array}$ & \multicolumn{2}{|c|}{$\begin{array}{c}\text { X-ray, CT } \\
\text { Scintigraph } \\
\text { MRI } \\
\text { *QUANTITATE MRI } \\
\text { and X-ray }\end{array}$} & $\begin{array}{c}\text { X-ray, CT only } \\
\text { * Quantitate on X-ray }\end{array}$ & X-ray only \\
\hline Location & NO & Medial & \multicolumn{2}{|c|}{ Central } & Lateral & NO \\
\hline \multirow[t]{5}{*}{ Size } & NO & \multicolumn{4}{|c|}{ Quantitation } & NO \\
\hline & & & $\begin{array}{l}\% \text { Area in- } \\
\text { volvement }\end{array}$ & $\begin{array}{l}\text { Length of } \\
\text { crescent }\end{array}$ & $\begin{array}{c}\text { \% surface collapse dome } \\
\text { depression }\end{array}$ & \\
\hline & & Minimal & $A<15 \%$ & $\mathrm{~A}<15 \%$ & $\mathrm{~A}<2 \mathrm{~mm}$ & \\
\hline & & Moderate & В $15-30 \%$ & $\begin{array}{l}\text { B } 15- \\
30 \%\end{array}$ & B $2-4 \mathrm{~mm}$ & \\
\hline & & Extensive & $C>30 \%$ & $C>30 \%$ & $\mathrm{C}>4 \mathrm{~mm}$ & \\
\hline
\end{tabular}

Table 1: ARCO's Classification.

Citation: Sudhir Babhulkar and Sushrut Babhulkar. "Bilateral Osteonecrosis of Femoral Head in Sickle Cell Disease: Salvage by Early Surgical Treatment in Single Sitting". Acta Scientific Orthopaedics 2.10 (2019): 16-23. 
the iliac crest about $5 \mathrm{~cm}$ posterior to Anterior superior iliac spine and up to the base of greater trochanter in the subtrochanteric region. The iliac crest is exposed, freed subperiosteally from inner lip by erasing three abdominal muscles, just to reach about $2 \mathrm{~cm}$. Similarly the iliac crest with attached tensor fascia lata on external surface should be exposed. An incision is made between anterior and middle fibers of TFL and clearly $2-3 \mathrm{~cm}$ width of TFL middle fibers are separated up to the iliac crest. With power saw osteotomy of iliac crest is done superiorly, and about $2 \mathrm{~cm}$ distally and medially which allows pedicle of TFL graft to move distally 6 . This isolated iliac crest graft with TFL pedicle is best done by subperiosteal separation of muscles on inner side of lip of the ilium without disturbing the vascular supply. The desired size of TFL with full or partial width of iliac crest was raised and pulled downwards with attached fibers of TFL. The TFL muscle pedicle graft just prepared gets its vascular supply from the superior gluteal artery and ascending branch of lateral circumflex femoral artery. The reflected pedicle of TFL were erased from the outer surface of ilium and is retracted downwards and brought down up to the anterior capsule of the involved hip joint. The hip capsule is then opened with $\mathrm{T}$ shaped incision. The ischemic necrotic segment is visualized under image intensifier for its deformation and change in the contour. A small window is made anteriorly at the junction of articular surface of the femoral head and anterior surface of the neck of the femur by pneumatic drill. Under image intensifier through this window, serial reaming from 4.5 to $12-14 \mathrm{~mm}$ is done in the ischemic segment of the femoral head right up to the subchondral region in all the directions. Care is taken not to perforate the articular surface. Subsequently the entire necrotic tissue was removed by curettage, which created a big void in the head of the femur usually in the superolateral quadrant of the femoral head, wherein inferior quadrant was usually not disturbed. With the special instrument and punch-impactor the deformed femoral head with articular cartilage is raised superiorly to match its original contour under image intensifier. The created void is partially filled and packed with few chips of cancellous bone removed from the iliac crest after performing the osteotomy. Subsequently the

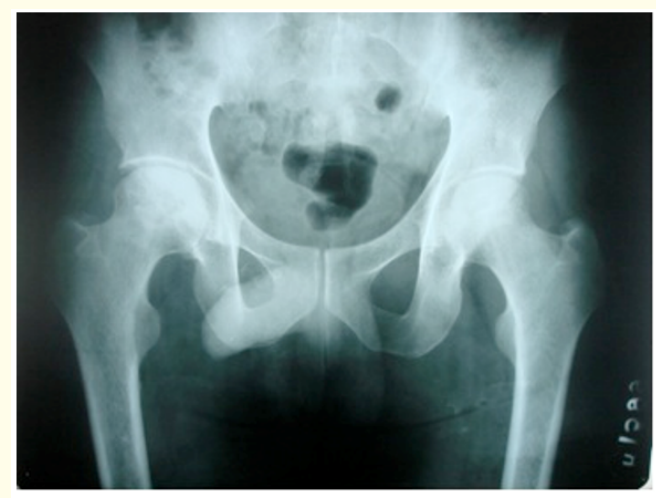

Figure 1: A. Plain X-ray (AP View) showing involvement of both hips with early changes changes of osteonecrosis (stage III)Multiple sclerotic densities without deformation of femoral head. Diagnosis was confirmed by MRI. retracted and raised pedicle of TFL with iliac crest is prepared nicely to repose through the window created at the head neck junction. Subsequently the TFL pedicle is impacted in to the head under image control right up to the subchondral region of femoral head and the graft tied by No.1 Vicryl to the femoral neck. The suction drain is kept at the hip and iliac crest site and wound is closed in layers. In bilateral cases with stage III involvement, the similar procedure is performed in the same sitting on the opposite side (Figure 1.A to C).

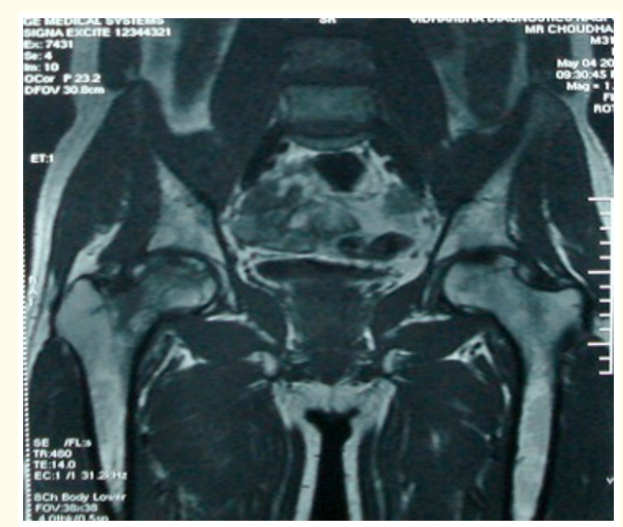

Figure 1: B. MRI pelvis showing changes of Osteonecrosis, Stage III in both hips without deformation of femoral heads.

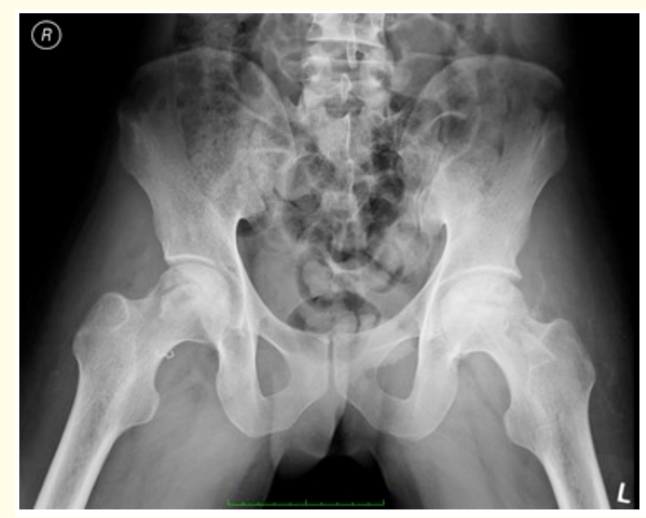

Figure 1: C. 2 months Post-Operative X-ray showing Bilateral core decompression and TFL pedicle grafting.

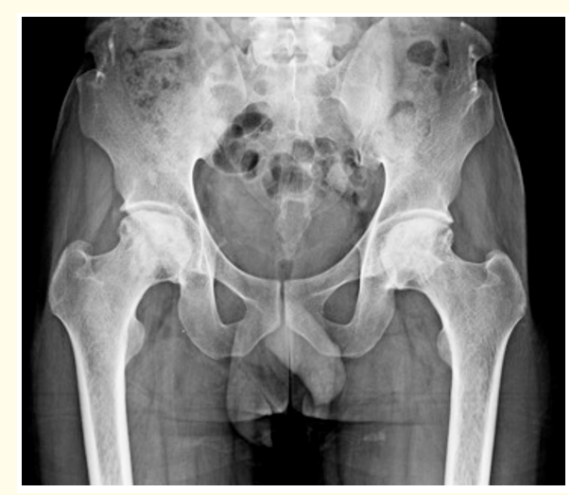

Figure 1: D. 18 months Post-Operative X-Ray (AP-View) showing good revascularization of both femoral heads without any arthritic changes. Osteotomy site of TFL graft can be seen at both Iliac crest. 


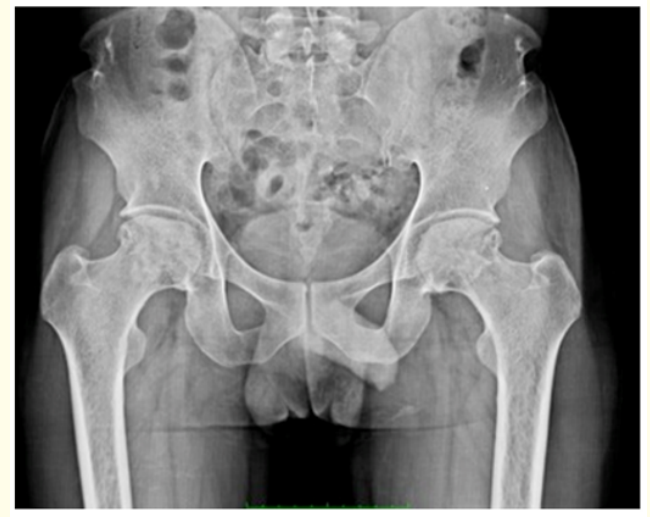

Figure 1: E. 5 years post-Operative $X$ ray showing good revascularization of both femoral heads by TFL graft. Osteotomy site of TFL graft can be seen at both Iliac crest.

In addition to TFL grafting in stage III on one side, the other asymptomatic osteonecrosis -stage II in the contralateral hip, were treated in the same sitting by Core decompression (Figure 2. A to $\mathrm{C}$ ). A small incision at the base of trochanter was made laterally and trochanter exposed after splitting tensor fascia lata and vastus lateralis. Under image intensifier core decompression was performed by using 4.5 drill bit in the multiple direction towards the ischemic segment, right up to subchondral region, taking precaution not to perforate articular surface. The wound was closed in layers.

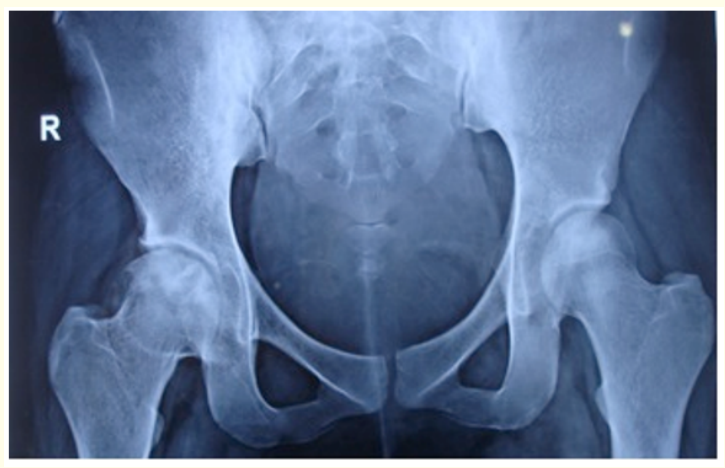

Figure 2: A. Pre-Operative X-ray (AP View) showing involvement of both hips with early changes left side (stage II) and advanced changes right hip (Stage III) without any deformation.

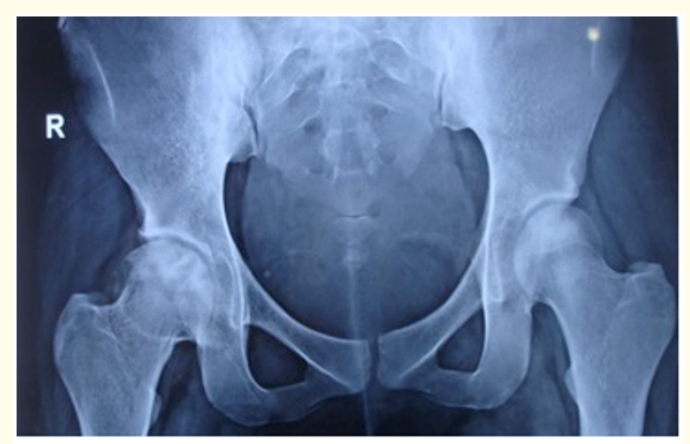

Figure 2: A. Pre-Operative X-ray (AP View) showing involvement of both hips with early changes left side (stage II) and advanced changes right hip (Stage III) without any deformation.

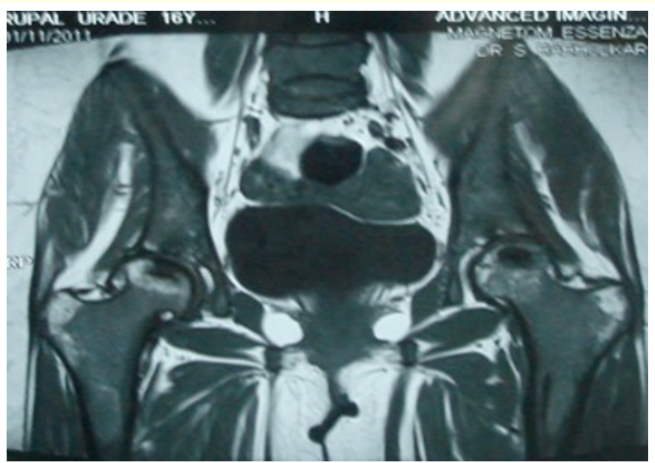

Figure 2: B. Pre-Operative MRI pelvis showing changes of Osteonecrosis both femoral heads.

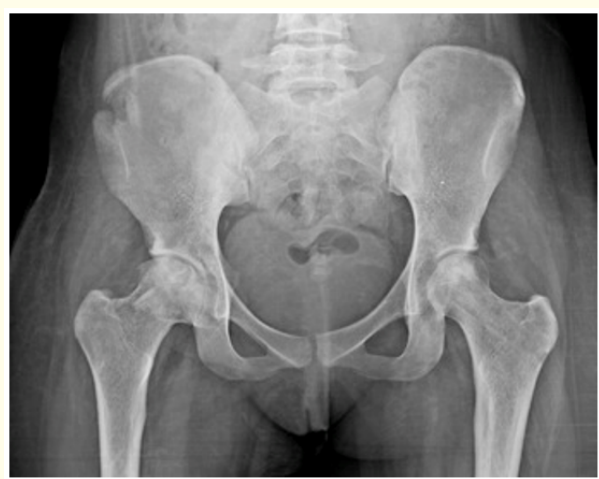

Figure 2: C. 2 months Post -Operative X-ray (AP View), Core decompression and TFL pedicle graft right side and Multiple Core Decompression on left side. 


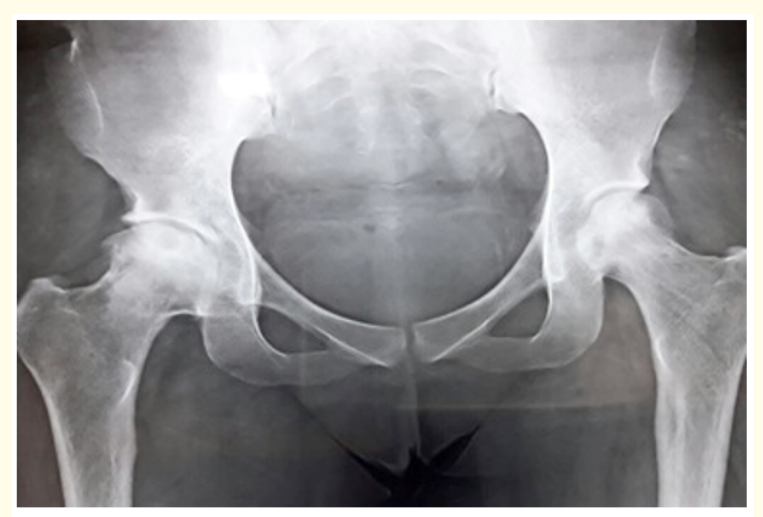

Figure 2: D. 6 years Post-Operative X-ray (AP View) showing complete revascularization of both the femoral head. Inspite of stage III right side no arthritic changes are noticed at the end of 6 years.

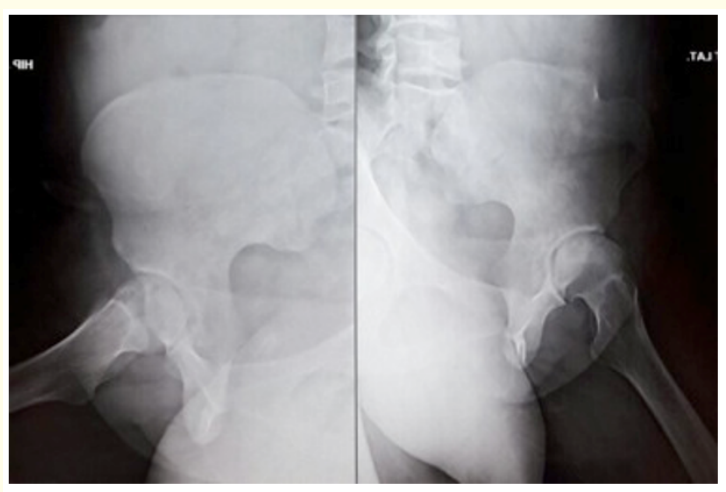

Figure 2: E. 6 years Post -Operative X-ray (Frog Leg View), showing complete revascularization of both the femoral head. Inspite of stage III right side no arthritic changes are noticed at the end of 6 years.

\section{Postoperative protocol and Follow-up}

Postoperatively the limb-Hip is kept in 20-degree abduction and 30 degree flexion and 10 degree of internal rotation to avoid tension on the TFL pedicle for 10 days. The patient was mobilized after 10 days in bed and after 6 weeks patient were mobilized out of bed on non-weight bearing crutch walking on TFL side and full weight bearing on contralateral hip where only core decompression is performed. If TFL grafting was performed on both hips, mo- bilsation of hips in bed was done after 4 weeks and partial weight bearing started after 10 weeks only, depending upon the quality of bone. The patients were allowed full weight bearing after 14-16 weeks.

Follow-up by clinical and radiological examination was done every 3 months for one year, every six months for next five years and then yearly follow up thereafter (Figure $1 \mathrm{D}$ and E), (Figure 2. D and E). Harris hip score system was used for assessment of the results. The follow up period varied from five years to eight years. Post operatively Bone scan and Digital subtraction arteriogram was done in only fourteen patients, at the end of 12 weeks, which showed hundred percent of patency and viability of the TFL muscle pedicle graft.

\section{Results}

Most of the patients had good clinical improvement with relief from pain and improvement in the range of movements. The radiological improvement was judged by diminishen of density and attempt at revascularization as seen by healing of cystic changes, disappearance of crescent sign and restoration of normal trabecular pattern and shape of femoral head. As per Harris Hip score results, there was improvement in the score of $>25$ points in $70 \%$ cases while in thirty \% had improvement in the score of more than 28 points in both the stages. The mean +SD improvement in Harris Hip score at 3 year's follow up was $33+6.4$. The difference in the preoperative and postoperative score across the whole sample was significant $(\mathrm{P}<0.05)$.

\section{Stage II (30 hips)}

Seventy percent of stage II hips completely improved without any deterioration (21 hips) and had complete relief from pain. Twenty percent patient had mild pain; though radiologically there was no deterioration (6 hips). Where as 3 hips (10\%) progressed to deformation, but had no collapse and had residual mild pain.

\section{Stage III (58 hips)}

About 12 hips (20\% hips) of stage III had residual low intensity pain for about 30 weeks. About 20 hips (30\% hips) had painless limp for 24-30 weeks with restriction of flexion beyond 100 Degrees. Eight percent hips (5 hips) progressed to further collapse, got deformed but without any progression to arthrosis. Out of this, in four percent patients (3 hips) surgery of total hip joint was advised and performed at the end of two years follow up. 21 hips 
(42\%) treated by core decompression and TFL grafting had full recovery with painless mobile hips.

\section{Discussion}

The incidence of osteonecrosis of femoral head is steadily increasing amongst the patients of Sickle cell haemoglobinopathies. The clinical entity is commonly seen in young adults between the ages of 20-40 years in the region of Central India and is frequently bilateral $[1,6,7]$. It is observed that anterolateral segments of femoral head superiorly undergo necrosis first and quickly. This is probably because of occlusion of posterolateral retinacular vessels by emboli from various sources finding their way through the microcirculation into the subchondral zone of femoral head. Bony changes in Sickle cell diseases occur mainly because of hyperplasia of bone marrow and because of vascular insufficiency resulting into thrombosis and infarction. Early diagnosis is the key to the success of head preserving operations, but once there is collapse of head with involvement of more than $60 \%$ of the weight-bearing surface, it may be necessary to perform total hip replacement of hip joint so as to rehabilitate these disabled patients.

After confirmation of Sickle cell disease by haematology and finding the amount of fetal haemoglobin percentage the patient is subjected to further radiological investigations. Presently our philosophy is changed and Isotope Bone scanning and sequential MRI studies closely monitor all patients of Sickle cell haemoglobinopathy, which are in extremely high-risk category $[6,7]$. In a high index suspicion patient of osteonecrosis of femoral head Bone Scanning are of great value if the X-rays are negative. Limitation of internal rotation and presence of Axis deviation test is highly suggestive of Osteonecrosis of femoral head. All the investigations are unnecessary if the X-rays are positive. Although X-ray examination is of limited value in making early diagnosis, it has considerable value in staging [8,10-12].

Rationale for the treatment of osteonecrosis of femoral head requires a lot of consideration. Prime importance in this is the age of patients, whether both hips are affected, and type of the associated Sickle cell disease, demands and requirement of the patients and the stage of the disease when the patient presents for the treatment is equally important. The treatment was planned according to ARCO's classification, which has combinations of: Ficat and Arlet classification, Quantification of Steinberg staging and location as Japanese Investigation committee [10-13].
Few authors reported the evidence to suggest that osteonecrosis in Sickle cell disease in early stages, the changes are reversible and they reported several patients of osteonecrosis treated by strict non-weight bearing gained both symptomatic and radiographic impairment [14]. Once the changes have advanced, there is little chance of improvement and surgery is the only option. It is believed that once crescent sign appears and there is a collapse of necrotic bone segment, even if it is minimal on x-ray, further collapse is inevitable and hip joints is likely to degenerate [15,17-20]. Any procedures like core decompression and bone grafting which is likely to revascularise the dead segment is not going to be useful once the collapse of segment occurs. Hence it is desirable to catch the patient before crescent sign appears or before femoral head starts collapsing $[6,7,18]$.

Barring exceptional circumstances, there is hardly any role of conservative treatment of osteonecrosis of femoral head and surgery is inevitable. Steinberg et al reported that progression occurred in $92 \%$ of 48 hips that had undergone non-operative management [8]. While observing the patients with protected weight bearing, more than $85 \%$ patients had collapse of femoral head at 2 years when symptomatic hips with stage I and II were left untreated [20]. No drugs have been useful and specific in the treatment of osteonecrosis, though recently the use of Alendronate has been advised. Non-weight-bearing conservative management of ischaemic necrosis has not been proved to be beneficial and hence various operative procedures are performed depending upon the stage of necrosis of femoral head.

Head preserving surgeries were done in stage III consisting of core decompression and bone grafting and in stage II only core decompression. Aim of the treatment at this stage is to reduce the ischaemia, intraosseous tension and perform the procedure, which will cause early revascularisation of ischaemic head. Only core decompression was done in asymptomatic stage II patients (whenever bilateral involvement was seen where contralateral hip involvement was asymptomatic and diagnosis was established by MRI and bone scan and there was no deformation of femoral head).

Core decompression is an effective treatment in the pre-radiological and precollapse stage of avascular necrosis of the femoral head, especially if coupled with bone grafting [16,17]. Jones analyzed nine studies and showed that in 218 of 369 patients (59\%), 
where core decompression was performed in the precollapse stage, failed to prevent the progressive collapse [20]. Steinberg et al concluded that core decompression provided more predictable pain relief and changed the indications for arthroplasty more consistently than conservative management [8].

Use of muscle pedicle graft and vascularised pedicle graft is more advantageous since high percentage of marrow and osteogenic cells survive within a living graft, which helps for early vascularization $[7,17]$. Though at our institute, many patients of osteonecrosis are studied and treated by vascular pedicle graft from the iliac crest along with pedicle from deep circumflex iliac artery, this procedure of vascular pedicle grafting was not performed on any patients of Sickle cell disease because of bilaterality and the possibility and high prevalence of thrombo-embolism in the vascular tree in this disease [7].

The rationale of this procedure of TFL muscle pedicle grafting is based on the following three points $[6,7]$

1. Decompression of the femoral head, which acts as compartment syndrome following increased intraosseous pressure and interrupts the circulation that is thought to contribute to the disease.

2. Excision of the necrotic tissue, which inhibits revascularization of the head.

3. Filling of the void that is created after core with TFL muscle pedicle graft with an osteoinductive cancellous bone graft, which is a viable and supports the subchondral surface and enhances the revascularization process.

\section{Conclusion}

If properly followed osteonecrosis in Sickle cell patients can be diagnosed in early stages. Proper vigilance, early bone scans and sequential MRI should be performed in high-risk patient when osteonecrosis is suspected. If osteonecrosis of femoral head in Sickle cell disease is diagnosed early, head preserving operation of core decompression, Core decompression and TFL muscle pedicle bone grafting yield good to excellent results in early stages of II and III. Ninety percent's patients in stage II and seventy two percent's in stage III had good results in osteonecrosis in Sickle cell disease patients. Only eight percent's patients deteriorated who required hip replacement surgery.

\section{Bibliography}

1. Babhulkar SS. "Osteonecrosis of the femoral head (in young individuals)”. Indian Journal of Orthopaedics 37 (2003): 77-86.

2. Diggs LW. "Bone and joint lesions in Sickle cell disease". Clinical orthopaedics and related reaserch 52 (1967): 119.

3. Chung and Ralston. "Necrosis of femoral head in Sickle cell disease". JBJS 51A (1969): 33-58.

4. Hernigou P., et al. "Natural history of hip necrosis in Sickle cell disease". Revue de Chirurgie Orthopédique 75.8 (1989): 542557.

5. Kozinn SC and Wilson PD Jr. "Adult hip disease and total hip replacement". Clinical Virology Symposium 39 (1989): 1-32.

6. Babhulkar Sudhir. Osteonecrosis Femoral Head Treatment by Core Decompression and ILIAC CREST-TFL Muscle Pedicle Grafting, Bone Grafting book by INTECH, Dr Alessandro Zorzi (Ed.), Sudhir Babhulkar (2012).

7. Babhulkar Sudhir. "Osteonecrosis femoral head: Core decompression and vascular pedicle grafting". Indian Journal of Orthopaedics 43.1 (2009): 27-35.

8. Steinberg ME., et al. "The conservative management of avascular necrosis of the femoral head". In: Arlet A, Ficat RP, Hungerford DS, editors. Bone circulation. Baltimore: Williams and Wilkins. (1984): 334-337.

9. Stulberg BN., et al. "Osteonecrosis of the femoral head: A prospective randomized treatment protocol". Clinical Orthopaedics and Related Research 268 (1991): 140-151.

10. Gardeniers JW. ARCO international classification of osteonecrosis. ARCO News 5 (1993): 79-82.

11. Steinberg ME., et al. "Treatment of avascular necrosis of the femoral head by combination of bone grafting, decompression and electrical stimulation". Clinical Orthopaedics and related research 186 (1984):137-153.

12. Ficat RP. "Idiopathic bone necrosis of femoral head. Early diagnosis and treatment". The Journal of Bone and Joint Surgery [Am.] 67-B (1985): 3-9.

13. Steinberg ME., et al. "A quantitative system for staging avascular necrosis". The Journal of Bone and Joint Surgery 77B (1995): 34-41. 
14. Chung SMK., et al. "Management of osteonecrosis in sickle cell anaemia and its genetic variants". Clinical Orthopaedics and related research 130 (1978): 158-174.

15. Kenzora JE and Glimcher MJ. "Accumulative Cell Stress: the multificatorial etiology of idipathic osteonecrosis". Orthopaedic Clinics of North America 16.4 (1985): 669-679.

16. Meyers MH. "The treatment of osteonecrosis of the hip with fresh osteochondral allografts and with the muscle-pediclegraft technique". Clinical Orthopaedics 130 (1978): 202- 209.

17. Baksi DP. "Treatment of osteonecrosis of the femoral head by drilling and muscle pedicle bone grafting". The Journal of bone and joint surgery. British volume 73-B (1991): 241-245.

18. Hungerford DS and Jones LC. "Diagnosis of osteonecrosis of the femoral head". In Schoutens A, Arlet J, Gardeniers JWM, et al. (eds): Bone Circulation and Vascularisation in Normal and Pathological Conditions. New York, NY, Plenum Press, (1993): 265-275.

19. Ficat P., et al. Ischaemia and Necrosis of Bone. Baltimore, MD, Williams and Wilkins (1980).

20. Jones JP Jr Fat embolism. "Intravascular coagulation, and osteonecrosis”. Clinical Orthopaedics (1992): 41-53.

\section{Volume 2 Issue 10 October 2019}

(C) All rights are reserved by Sudhir Babhulkar and

Sushrut Babhulkar. 